\title{
Um Boom de Mídias na Infância: Reflexões acerca do Uso de Tecnologias Digitais na Educação Infantil
}

\author{
Gabryelle Chaves Ferreira1, Maria Auricélia da Silva², Thiago de Sousa Garcia ${ }^{3}$ \\ 1Faculdade de Educação - Universidade Federal do Ceará (UFC) - Campus do Pici - \\ Rua Waldery Uchôa, 01 - Benfica, Fortaleza - CE, 60020-060 - Fortaleza-CE \\ 2Unidade Universitária de Educação Infantil Núcleo de Desenvolvimento da Criança - \\ Universidade Federal do Ceará (UFC) - Campus do Pici - Bloco 859 - Fortaleza-CE. \\ ${ }^{3}$ Departamento de Computação - Universidade Federal do Ceará (UFC) - Campus do \\ Pici - Bloco 910, Fortaleza-CE \\ gabryelle30chaves@gmail.com, silvauricelia@gmail.com, \\ tsousa900@gmail.com
}

\begin{abstract}
This study investigates the interests of children on the childhood education by the use of digital resources out of school, the way that they use this instruments on their routine and the time what they spend on activities of this character compared by other research, already done in 2016. The interpretative paradigm and the quali-quantitative approach constituted the main pillar of the research. The data were collected through a questionnaire applied to the families of the children, with the purpose of probing the interests and uses that they make of the digital resources to which they have access. The results indicate that the children show great proximity with the digital resources, what allows to use that as a pedagogical resource.
\end{abstract}

Resumo. Este estudo investiga os interesses de crianças da Educação Infantil pelo uso de recursos digitais fora da escola, a forma como elas usam esses instrumentos em seu cotidiano e o tempo que consomem em atividades dessa natureza em comparação com outra pesquisa, realizada em 2016. O paradigma interpretativo e a abordagem quali-quantitativa constituíram o principal pilar da pesquisa. Os dados foram coletados por meio de um questionário aplicado aos familiares das crianças, com a finalidade de sondar os interesses e usos que elas fazem dos recursos digitais aos quais têm acesso. Os resultados indicaram que as crianças mostram grande proximidade com as tecnologias digitais, o que possibilita utilizá-las como recurso pedagógico.

\section{Introdução}

As tecnologias datam da Antiguidade, por isso são tão arcaicas quanto a espécie humana que, desde o início de sua existência, cria métodos para incrementar suas ocupações e reduzir vulnerabilidades [Kenski 2012]. Sendo assim, a disseminação da tecnologia e o domínio divulgado por meio das mídias tem adentrado cada vez mais o cotidiano dos 
indivíduos, propiciando o crescimento de novas habilidades por meio das inúmeras linguagens existentes.

Atualmente, a maior indagação que se apresenta não é se os artefatos digitais devem ser utilizados na educação, mas como usá-los, com o objetivo de favorecer o desenvolvimento e a aprendizagem das crianças [Machado 2013]. Dessa forma, a área da educação é, costumeiramente, sondada no que diz respeito às suas estratégias pedagógicas para contemplar o avanço das tecnologias que estão, de fato, inseridas no dia a dia das novas gerações que frequentam as turmas de Educação Infantil.

Nessa perspectiva, as Tecnologias Digitais de Informação e Comunicação (TDIC) dispõem de princípios que contribuem para a reformulação da comunicação interpessoal e, assim, inserem-se na escola como resultado do que é vivenciado na sociedade. Desse modo, o acesso a recursos digitais e à Internet passa a ser um fator positivo na forma como o trabalho escolar é encarado por professores e alunos, a partir das metodologias utilizadas nos processos pedagógicos.

Torna-se válido evidenciar que o termo tecnologias não se refere somente a aparelhos e equipamentos, mas também a uma infinidade de componentes concebidos pelo ser humano em diferentes tempos, formas de utilização e aplicabilidade [Kenski 2012].

Por meio da utilização das TDIC, o mundo concreto vivenciado pelas crianças fora da escola pode ser introduzido no contexto escolar, priorizando o questionamento e a criatividade como fatores da aprendizagem dos alunos [Coll e Monereo 2010]. A partir disso, é pertinente refletir acerca do uso das mídias digitais na Educação Infantil e a relevância de seu uso pedagógico para crianças pequenas.

Desse modo, o uso pedagógico de recursos digitais torna-se fundamental, visto que as crianças estão, cada vez mais, imersas na cultura digital e utilizam recursos tecnológicos, principalmente tecnologias móveis, e começam a utilizar essas mídias cada vez mais cedo. Staa (2011 p. 44) enfatiza que "essas crianças manuseiam telefones celulares antes de saber falar, operam computadores, mouses e telas de toque sem que ninguém lhes ensine a fazer isso".

É necessário, pois, aliar aspectos lúdicos e pedagógicos a recursos tecnológicos que sejam vinculados à Internet, visto que tal uso pode auxiliar no processo de ensino e aprendizagem em qualquer etapa da Educação Básica. No que se refere ao atual público infantil, que já nasceu em um mundo globalizado, pode-se afirmar que já são integrantes da cultura digital que os cerca, pois "os sujeitos que nasceram imersos no mundo digital interagem, simultaneamente, com as diferentes mídias" [Alves 2008 pp. 6 e 7].

Nessa perspectiva, o presente estudo foi realizado com o objetivo geral de investigar os interesses das crianças pelo uso de recursos digitais, como elas os utilizam em seu cotidiano e o tempo que consomem em atividades dessa natureza.

A abordagem da pesquisa é quali-quantitativa e a análise dos dados se deu por meio da interpretação de referenciais teóricos e dos dados levantados na pesquisa realizada com os familiares das crianças, que tratam de temáticas relevantes sobre as mídias e a Educação Infantil.

Para a coleta de dados, foi elaborado um questionário e aplicado aos familiares de todas as crianças matriculadas na Unidade Universitária de Educação Infantil Núcleo de 
Desenvolvimento da Criança (UUNDC/UFC). Esta etapa foi importante para a compreensão dos interesses infantis e das atividades que as crianças conseguem realizar utilizando recursos digitais, além de ações que poderão ser implementadas nas práticas pedagógicas com suporte digital.

Os resultados preliminares indicam que as crianças demonstram grande interesse e familiaridade com os recursos digitais, consomem várias horas do dia utilizando algum tipo de recurso tecnológico, conseguem realizar muitas ações, divertem-se e aprendem com esse tipo de atividade.

\section{Metodologia}

O presente estudo foi estruturado mediante uma abordagem quali-quantitativa, em que foi usado o método misto de pesquisa (mixed model research), procurando integrar procedimentos quantitativos e qualitativos [Bogdan e Biklen 1994]. A combinação desses métodos pode utilizar-se dos benefícios que as duas metodologias possuem, ao mesmo tempo em que supre suas lacunas. Logo, a pesquisa a partir do método misto abrange questões mais completas, superando as limitações de uma só abordagem [Spratt, Walker e Robison 2004].

Os dados aqui apresentados foram coletados por meio de um questionário aplicado aos familiares de todas as crianças matriculadas na Unidade Universitária de Educação Infantil Núcleo de Desenvolvimento da Criança (UUNDC/UFC), com o propósito de sondar os interesses e usos que as crianças fazem dos recursos digitais aos quais têm acesso. A UUNDC atende crianças de três a seis anos, portanto turmas de Infantil 3, Infantil 4 e Infantil 5.

O questionário foi elaborado de maneira sistemática e sequencial, objetivando promover a interlocução desejada entre o pesquisador e os sujeitos investigados por meio de respostas escritas [Chizzotti 1998].

Os questionários foram enviados aos familiares de todas as crianças regularmente matriculadas na UUNDC no dia 29/04/2019 e foram devolvidos por eles após duas semanas, no máximo até 13/05/2019. Foram distribuídos 55 questionários nas quatro turmas existentes: Infantil 3A, Infantil 3B, Infantil 4 e Infantil 5. Desses, foram devolvidos 45 questionários, o que corresponde a aproximadamente $82 \%$ da população, portanto uma amostra significativa.

Os dados coletados foram tabulados, sistematizados em tabelas e gráficos com o suporte da planilha Excel e serão apresentados a seguir.

\section{Resultados e discussão}

A faixa etária das crianças regularmente matriculadas na UUNDC/UFC variava entre 3 a 6 anos até o dia 13/05/2019, prazo máximo para devolução dos questionários respondidos pelos familiares. Conforme explicitado anteriormente, estão matriculadas 55 crianças no ano letivo de 2019, distribuídas em duas turmas de Infantil 3, uma turma de Infantil 4 e uma turma de Infantil 5. Desse total, dez (10) famílias não devolveram o questionário, motivo pelo qual a análise dos dados coletados diz respeito a 45 sujeitos.

A distribuição etária é a seguinte: 20 crianças com 3 anos; 14 crianças com 4 anos; 9 crianças com 5 anos e 2 crianças com 6 anos. Considerar a idade das crianças nesta pesquisa é relevante devido ao fato de que, mesmo muito novas, as crianças começam a 
utilizar recursos digitais e, no decorrer de seu crescimento, as ações que desempenham tornam-se mais complexas e elaboradas.

Acerca do interesse que as crianças demonstram pelo uso de recursos digitais, as respostas indicaram que 40 crianças, o que corresponde a $89 \%$ dos sujeitos, demonstram interesse em usar artefatos tecnológicos constantemente e, apenas 5 crianças, $11 \%$ delas, interessam-se eventualmente.

É importante observar que todas as crianças pesquisadas interessam-se por recursos digitais em maior ou menor grau. Sendo assim, é perceptível que as crianças têm acesso a algum tipo de recurso tecnológico, e tal aparato lhes desperta certo grau de interesse. Logo, todas demonstram desejo de utilizar tecnologias digitais, como pode ser observado no Gráfico 1.

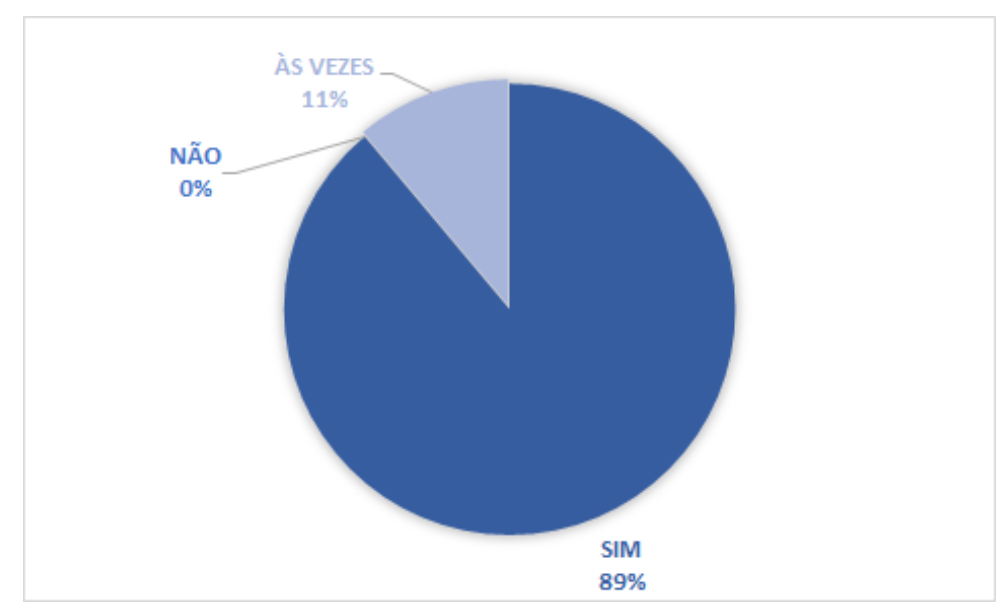

Gráfico 1. Interesse das crianças por recursos tecnológicos

Os dados apresentados nesta pesquisa confirmam os achados da investigação realizada por Silva e Macedo Filho (2016), que encontraram dados semelhantes a estes aqui apresentados, quando realizaram um estudo com turmas de Educação Infantil na mesma instituição, pesquisada em 2016, acerca dos interesses das crianças pelo uso de mídias digitais. Na época, todas as crianças já demonstravam interesse pelo uso de recursos digitais, sendo que $92 \%$ demonstravam interesse constante e apenas $8 \%$ delas demonstravam interesse eventual.

Santaella (2012 p. 49) reconhece que "as mídias tendem a se engendrar como redes que se interligam e nas quais cada mídia particular - livro, jornal, TV, rádio, revista etc. - tem uma função que lhe é específica". Assim sendo, é importante que as crianças vivenciem experiências que incluam diferentes recursos midiáticos também na escola.

Quando são utilizados recursos digitais com as crianças, percebe-se que atividades com imagens, movimento e sons favorecem a aproximação entre as experiências vivenciadas e a realidade que se apresenta às crianças cotidianamente. Então, a aprendizagem torna-se mais interessante e significativa, pois a criança estabelece comparações entre o que está experimentando e o seu contexto social, o que pode gerar maior interesse e envolvimento nas práticas escolares.

No que tange aos recursos mais usados pelas crianças, os familiares poderiam assinalar mais de uma opção no questionário aplicado. Como as tecnologias móveis são 
bastante acessíveis às pessoas em todos os lugares, o smartphone, o tablet e o laptop foram os mais citados, como consta no Gráfico 2.

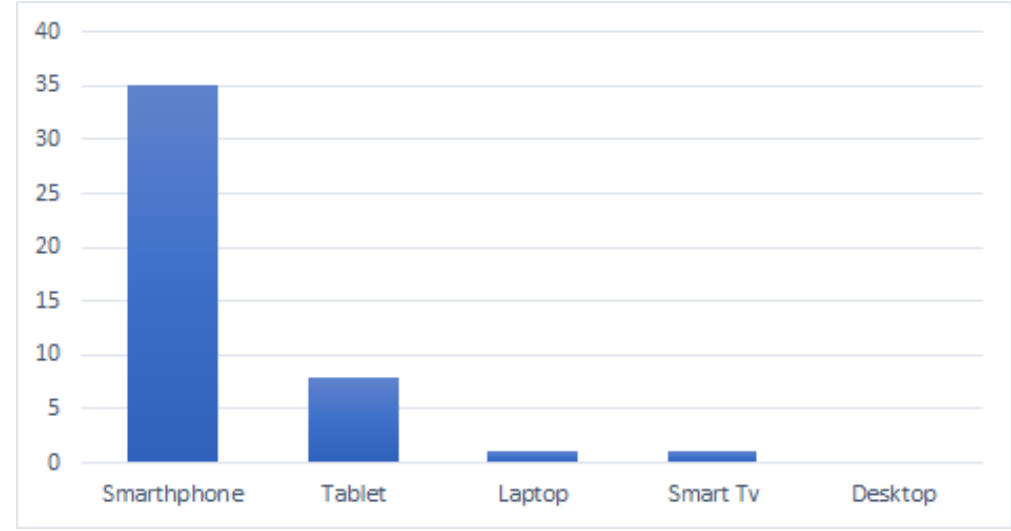

Gráfico 2. Recursos mais utilizados pelas crianças

Entre esses meios digitais, o smartphone foi classificado como o mais utilizado pelas crianças. Dos 45 indivíduos sondados, 35 manuseiam mais o smartphone e 8 usam mais o tablet. Somente 1 criança usa mais o laptop, nenhuma delas utiliza o desktop e, somente 1 utiliza frequentemente a Smart TV.

Os dados apresentados corroboram o uso de tecnologias móveis, com destaque para o smartphone e o tablet, também citados na pesquisa de Silva e Macedo Filho (2016). Contudo, percebe-se que houve um aumento considerável no uso de smartphones e tablets e a diminuição do uso de laptops e desktops. Na pesquisa anterior citada, 5 crianças usavam o laptop e 2 usavam o desktop. Em relação ao desktop, fica confirmado que as tecnologias móveis são mais utilizadas, a despeito de o laptop ser pouco utilizado na pesquisa atual. semana.

O gráfico 3 mostra a utilização de recursos digitais em dias úteis e nos finais de

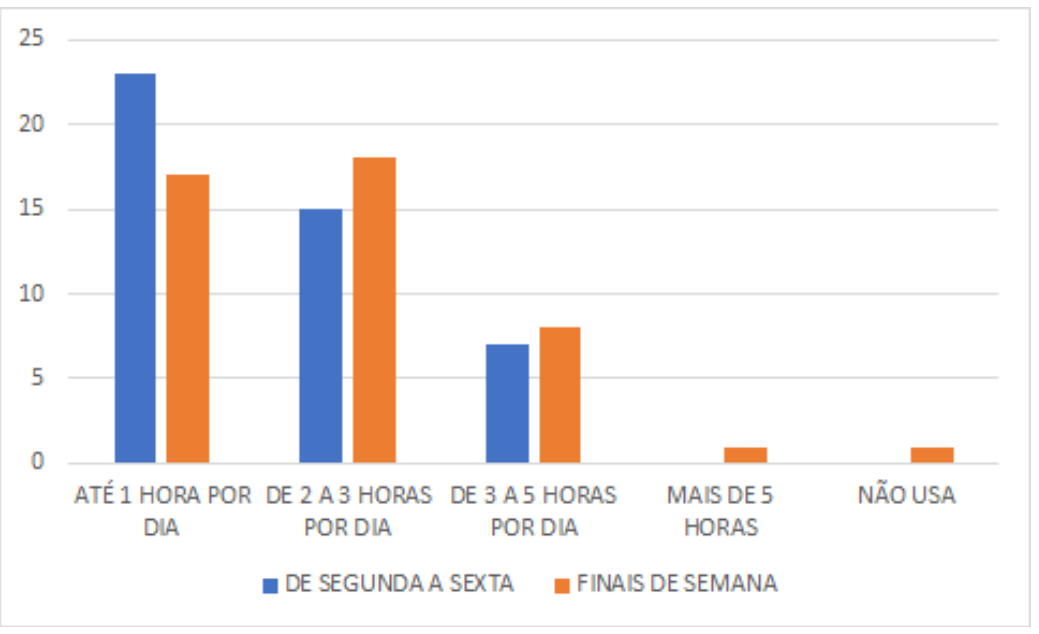

Gráfico 3. Tempo que as crianças dedicam ao uso de recursos digitais

Nos dias úteis, possivelmente devido aos horários escolares e às demais atividades que as crianças realizam, o acesso às tecnologias digitais fica em torno de uma hora diária, ao passo que, nos finais de semana, a maioria das crianças utiliza esses artefatos por um 
período de duas a três horas diárias. Esses dados são compatíveis com os encontrados na pesquisa de Silva e Macedo Filho (2016).

No que se refere às atividades que as crianças realizam enquanto utilizam recursos digitais, os familiares poderiam assinalar mais de uma opção porque, de fato, as crianças facilmente acessam diversos recursos. De acordo com as respostas dos familiares, predominam os seguintes usos: assistir a vídeos, usar jogos e tirar fotos, como pode ser observado no Gráfico 4.

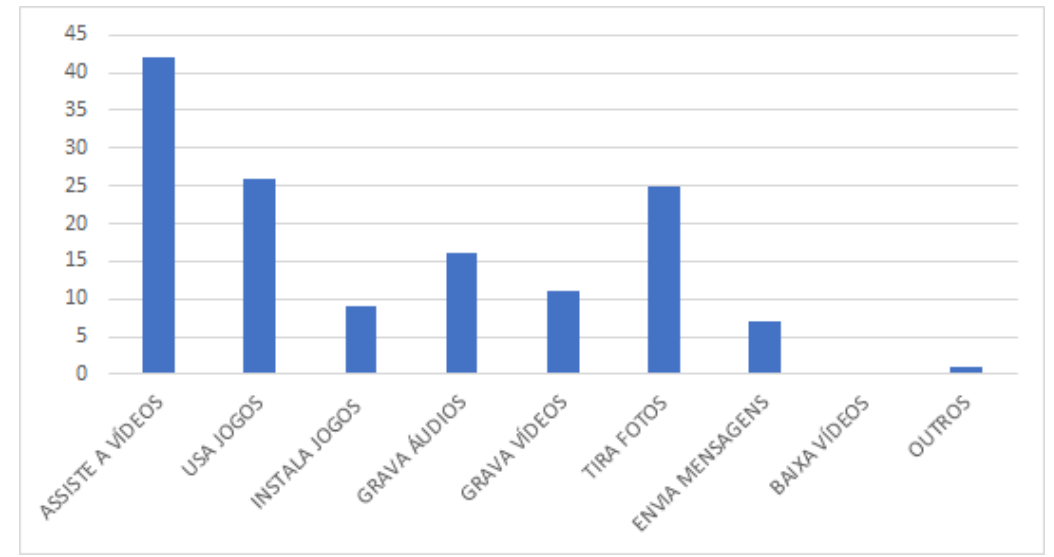

Gráfico 4. Atividades que as crianças realizam utilizando recursos digitais

Dialogando com a pesquisa realizada anteriormente por Silva e Macedo Filho (2016), os achados são compatíveis com a pesquisa atual. Nota-se que as crianças pequenas assistem mais a vídeos e gravam áudios, enquanto as maiores baixam os vídeos a que desejam assistir e já conseguem gravá-los. Por possuírem um acervo maior de vivências, as crianças de 4 e 5 anos enviam mais mensagens pelo smartphone do que as crianças menores.

Mediante os dados apresentados, observa-se o quanto as crianças estão envolvidas no mundo digital e como esse vínculo com as tecnologias pode interferir nas formas de se relacionarem com as pessoas, solucionarem problemas do dia a dia e aprenderem de forma lúdica. Machado (2013 p. 3) esclarece que

As tecnologias, aliadas às propostas curriculares da Educação Infantil, permitirão às crianças explorar novos conhecimentos, aprendendo a pesquisar, questionar, expressar sua opinião, pensar e elaborar ideias de maneira lúdica, interativa e divertida, tornando o processo de aprendizagem mais interessante.

Portanto, as instituições podem e devem iniciar o trabalho com tecnologias digitais como suporte ao trabalho pedagógico desde a Educação Infantil.

\section{Considerações Finais}

O presente estudo discute o fato de que, desde muito cedo, as crianças têm acesso a recursos digitais e apresentam um bom manuseio de tais ferramentas, evidenciando sua imersão na cultura digital difundida na sociedade.

Assim, é relevante ressaltar que, nos dados da pesquisa apresentada, todas as crianças demonstraram interesse pelo uso de recursos digitais, em maior ou menor grau. 
Desse modo, é necessário que a instituição escolar tome uma posição em relação a essa realidade e utilize tecnologias digitais como um recurso presente na vida das crianças, que pode contribuir com o seu desenvolvimento e a sua aprendizagem.

Infere-se, por meio desta pesquisa, que as crianças usam aparatos móveis constantemente, em particular o smartphone e o tablet, possivelmente porque são de fácil manuseio e acessíveis à população.

Portanto, de acordo com os dados apresentados, o smartphone é o recurso mais usado pelas crianças, principalmente nos finais de semana, quando dedicam mais tempo a atividades lúdicas.

Conforme seu desenvolvimento e suas aprendizagens, as crianças conseguem realizar mais atividades com um maior grau de complexidade, o que demonstra uma evolução na sua relação com os recursos digitais, quer seja para entretenimento, por meio de vídeos e jogos, ou para a comunicação, na forma de mensagens de voz.

Diante do que foi apresentado e discutido, o uso de tecnologias digitais na Educação Infantil reforça a convicção de que as mídias digitais auxiliam no desenvolvimento e na aprendizagem das crianças. Para tanto, é fundamental que haja um acompanhamento das atividades que elas realizam dentro do ambiente escolar e fora dele, quando utilizam esses recursos, a fim de se beneficiarem de seus aspectos positivos.

\section{Referências}

ALVES, Lynn. (2008) "Relações entre jogos digitais e aprendizagem: delineando percurso". In: Educação, Formação \& Tecnologias, vol.1(2); pp. 3-10, Novembro de 2008. Disponível em <http://eft.educom.pt.>. Acesso em: 30 jun de 2019.

BOGDAN, Roberto C. e BIKLEN, Sari Knopp. (1994) "Investigação qualitativa em educação”. Tradução Maria João Alvarez, Sara Bahia dos Santos e Telmo Mourinho Baptista. Porto: Porto Editora.

CHIZZOTTI, Antonio. (1998) "Pesquisa em Ciências Humanas e Sociais”. 3. ed. São Paulo: Cortez.

COLL, César e MONEREO, Carles. (2010) "Educação e aprendizagem no século XXI: novas ferramentas, novos cenários, novas finalidades". In: COLL, César; MONEREO, Carles. Psicologia da educação virtual: aprender e ensinar com as tecnologias da informação e educação. Porto Alegre: Artmed, 2010. Cap. 1.p. 15-45. Tradução: Naila Freitas.

KENSKI, V. M. (2012) "Educação e tecnologias: o novo ritmo da informação". Campinas, São Paulo: Papirus, 2012.

MACHADO, Márcia Regina. (2013) “A inclusão da tecnologia na educação infantil”. In: XI Congresso Nacional de Educação. Pontifícia Universidade Tecnológica do Paraná.

SANTAELLA, Lucia. (2012) “O papel do lúdico na aprendizagem”. In: Revista Teias, v. 13, n. 30, p. 163-173, set./dez. 2012.

SILVA, M. A. e MACEDO FILHO, J.A. (2016) "Mídias Digitais na Educação Infantil: uma reflexão necessária". In: XVIII Encontro Nacional de Educação Infantil. Universidade Federal do Rio Grande do Norte. Natal, Rio Grande do Norte. 
SPRATT, C.; WALKER, R.; ROBINSON, B. (2004) "Mixed research methods". Practitioner Research and Evaluation Skills Training in Open and Distance Learning. Commonwealth of Learning, 2004. Disponível em: http://www.col.org/SiteCollectionDocuments/A5.pdf. Acesso em: 28 jun. 2019.

STAA, Betina Von. (2011) Aproveitando a tecnologia para promover o desenvolvimento das crianças. Pátio Educação Infantil ano IX N 28 jul/set. 2011. 